\title{
perifèria
}

Número 7, mes 2005

www.periferia. name

\section{Percepción y rentabilidad cinegética: la hipótesis del "verdadero ecologista"}

\author{
Roberto Sánchez Garrido-Universidad de Murcia ${ }^{1}$
}

\section{Resumen}

La caza supone en el conjunto del estado español una actividad que junto a su importancia económica juega un factor destacado en la actuación, modificación y conservación de espacios naturales. El cazador se convierte en agente activo que a través de una práctica secular influye sobre los acotados y en la biodiversidad existente en ellos, adaptándola a sus necesidades. Este hecho parte de un concepto y una percepción medioambiental particular. Dentro de esta dinámica, atendiendo a los discursos emic, el cazador se arroga la auto-definición de "verdadero ecologista" en virtud a los trabajos que realiza en pro de la fauna cinegética y su hábitat. A ello se une la confrontación a ese "otro" ecologismo de asociaciones y colectivos ecologistas a los que consideran alejados de la "realidad" natural. El texto incide en la hipótesis de considerar que tanto la percepción como la actuación vienen determinadas por un concepto de rentabilidad, que el cazador y las empresas del sector activan según el caso en virtud de rentabilizar económica y/o recreativamente la inversión realizada. La figura del cazador como "verdadero ecologista" quedaría inmersa en una dialéctica entre un "discurso atávico" y un condicionante económico.

Palabras clave: Caza, Etnografía, Economía, Ecología.

\begin{abstract}
The hunting supposes in the set of the Spanish state an activity that together its economic importance plays an outstanding factor in the performance, modification and conservation of natural spaces. The hunter becomes an active agent who through a secular practice influences the fugitives and in the existing biodiversity in them, adapting it to his necessities. This fact is the beginning of concept and a particular environmental perception. Within this dynamics, taking care of the emic speeches, the hunter thinks of himself as a "true ecologist" due to the works that makes for the cinegetic fauna and its habitat. In addition the ecological confrontation to that "another" ecologism of associations and ecological groups to which they consider far anyway from the "natural reality". The communication affects the hypothesis to consider that the perception as much as the performance comes determined by a concept of profitability, that the hunter and the companies of the sector activate according to the case by virtue of making profitable economically and/or recreationally the investment done. The figure of the hunter as "true ecologist" would be immersed in a dialectic one between an "atavic speech" and an economic conditioner.
\end{abstract}

Keywords: Hunting, Ethnography, Economy, Ecology.

\footnotetext{
${ }^{1}$ Enviar correspondencia a: Roberto Sánchez Garrido, rgarrido@umh.es
} 


\section{perifèria}

Número 7, mes 2005

www. periferia. name

\section{Caza, cazador y mirada ${ }^{2}$}

La caza actual, en su vertiente deportiva-recreativa, puede considerarse como una de las actividades que mayor contacto e impacto tiene sobre el medio natural. La extensión de acotados de caza en España ronda el 70 \% del total del territorio, con una importancia económica, social y cultural que hunde sus raíces, sobre todo en lo referido a estos dos últimos aspectos, en una tradición secular. El impacto medioambiental de la caza varía en la medida en la que se lleva a cabo su práctica, si atendemos a la acción directa y al impacto que podría denominarse como efectivo. Pero más allá de éste, y en un plano igualitario en cuanto a su importancia, aparece el proceso cognitivo y la escala de valores que categoriza y conceptualiza esos impactos, con una serie de discursos colectivos, que en el caso más común y extendido defiende la caza como una actividad ecológica y al cazador como "verdadero ecologista".

Sergio dalla Bernardina (1996), en II ritorno a la Natura. L'utopia verde tra caccia ed ecologia, se adentra en la concepción que se tiene del medio natural desde la vertiente cinegética. La naturaleza se concibe desde las ciencias sociales como una construcción humana, interpretándose de esta forma la relación que el cazador establece con ella. El cazador tiene presente que la naturaleza "ya no es lo que era" y sus relaciones tampoco son las mismas, la caza no es ahora una forma de subsistencia, ni tiene un fin propedéutico para la guerra, sino que su sentido es otro así como las razones que llevan a su práctica. Existe, no obstante, un regreso a lo natural, lejos de la vida urbana, en la que el ser humano vuelve a ocupar su lugar. La naturaleza prístina que se busca está mercantilizada y la vivencia "auténtica" se compagina con la inversión realizada en la que "ogni cliente può godere di una dose di natura proporzionales alla quantità del denaro investito" (Dalla Bernardina 1996: 145).

\footnotetext{
${ }^{2}$ La reflexión que articula la narración nace de la investigación realizada para la tesis doctoral Actividad Humana y Naturaleza. La práctica cinegética y los usos del medio natural. El caso del parque natural de la Sierra del Carrascal de la Font Roja, presentada en el área de Antropología Social de la Universidad de Murcia.
} 


\section{perifèria}

Número 7, mes 2005

\section{www. periferia. name}

La percepción, la mirada y su relevancia cognitiva, hace que la interpretación de un mismo paisaje sea diferente según la persona y el colectivo que lo active. Un mismo territorio, un mismo entorno, una misma naturaleza será pensada y percibida de forma distinta, y a partir de ahí la actuación sobre ella también diferirá. El cazador tiene una determinada percepción en la que interpreta el medio natural atendiendo a su formación cinegética. Ortega y Gasset defiende que el cazador adopta una mirada especial, una mirada "preobjetiva" en la que todavía no ve las cosas como objetos, sino que es una mirada global que le hace estar alerta en el medio sin atender únicamente a uno de sus aspectos:

(...) el que es cazador y pasea por el campo con un agricultor nota pronto la diferencia entre el paisaje que ante sí tiene y el que existe para su acompañante. El agricultor, por ejemplo, no suele oír y, desde luego, no percibe distintamente los ruidos campesinos. Las lejanas voces de las aves no son por él reconocidas: los rumores mágicos de la campiña, que para el cazador son signos inequívocos de su claro mensaje telúrico, no dicen nada al que vive en el campo con el fin de explotarlo. Viceversa, ciertos detalles de la campiña notados por éste escapan al cazador; pero, en definitiva, no puede negarse que el paisaje del cazador es mucho más rico en objetos que el del hombre agrícola. Cien veces hemos advertido lo poco que saben de campo los campesinos (Ortega y Gasset 1995: 271).

Si bien es cierto que el cazador poseería esa mirada global en la que se integraría en el medio conociéndolo, atendiendo a sus aspectos generales, a lo físico, a lo vivo, a lo meteorológico, englobando las percepciones y conocimientos en pro de la consecución de un afán cinegético, la generalización dejaría fuera las actitudes particulares de los distintos individuos. En un colectivo tan amplio como heterogéneo, con unos intereses gestores altamente mercantilizados, los cazadores tienen a su vez una mediatización derivada no sólo de este hecho sino de sus propias circunstancias personales. Habría que preguntarse qué mirada preobjetiva puede tener aquel que se acerca al campo sin conocer nada de él, o conociéndolo pero influenciado por el impulso de captura. Es decir, esa mirada global pasa a la particularidad de un interés más concreto que el propiamente cinegético, un interés que no tiene en cuenta el medio, no ya en su respeto sino en el conocimiento que precisa para fundirse como elemento natural que busca la integración del superdepredador eventual, el cazador, con las especies cinegéticas. Las categorías de interpretación, lo 


\section{perifèria}

Número 7, mes 2005

\section{www. periferia.name}

preconcebido, lo prejuzgado, lo clasificado de antemano, no las ocultaría el cazador en su mirada, al contrario, las activaría en determinados momentos debido a la creación de discursos contextuales que derivarían en acciones concretas, lo que matizaría la generalización de la mirada preobjetiva. El regreso del hombre ${ }^{3}$ a la naturaleza a través de sus instintos atávicos, con lo que aún tiene de animal, es otro de los puntos mencionados por Ortega. Aparece aquí una historicidad en la que al hombre se le presupone un instinto y unas condiciones prístinas heredadas y ocultas en el quehacer diario, que se activan durante las experiencias cinegéticas. Si a nivel teórico las reflexiones de Ortega pasan por ser sugerentes, a nivel práctico hay que atender a toda una diversidad que si bien no pone en duda el andamiaje teórico filosófico sí que lo hace su praxis, con unas concepciones y unas actitudes que poco tienen que ver con los discursos que los cazadores ofrecen fuera del contexto cinegético y con los resultados observables en la interacción realizada en los cazaderos. Una de las críticas realizadas al análisis de Ortega ha sido la de centrarse en un tipo de cazador elitista, económicamente y socialmente, dejando de lado al cazador modesto y para el que, en la época en la que escribió sus textos, la caza era una fuente más de alimentos en un momento histórico marcado por el hambre.

\section{La mercantilización cinegética y el cazador como "verdadero ecologista"}

La caza vive desde hace décadas un proceso de comercialización que ha variado sustancialmente gran parte de las formas y actitudes de sus participantes, dejando a su vez un interesante diálogo entre dos tipos de construcciones teóricas, basadas en la comparación diacrónica de la acción cinegética a lo largo de los últimos años. Se puede hablar de un cambio acentuado en el valor y repercusión económica de la caza, con una evolución comercial de los métodos de gestión del medio, de una

\footnotetext{
${ }^{3}$ A lo largo del texto se utilizará el genérico masculino, la razón fundamental surge del componente masculino de la caza, donde la mujer tiene una representación muy puntual y donde el hombre es el protagonista, con la reproducción de un contexto que podríamos considerar, sin entrar en más consideraciones que se escaparían del objetivo del artículo, dentro de una masculinidad hegemónica tradicional.
} 


\section{perifèria}

\section{Número 7, mes 2005}

\section{www. periferia.name}

oposición en el discurso emic a la nueva realidad y de una adecuación a las formas actuales como única solución para seguir practicándola. Si bien es cierto que las intensidades de la mercantilización varían según los casos, no lo es menos que todos los acotados, de una forma u otra, están influidos por ésta.

La explotación cinegética, en la búsqueda de la rentabilidad económica, social o recreativa, tiene como objetivo el optimizar el terreno para la mejora y/o aumento de su población cinegética. Si se pone en valor un espacio para su rendimiento económico, la primera consecuencia sería la mejora del mismo para aumentar la calidad de la oferta, atrayendo a un mayor número potencial de clientes. Esto está estrechamente ligado a su impacto medioambiental, fluctuando en dos sentidos, el de un desarrollo ordenado y sostenible de las especies del acotado y el desequilibrio ecológico mediante la introducción, reintroducción o suelta de especies criadas en cautividad. El concepto de gestión cinegética nace de la necesidad de ordenar de alguna forma las nuevas necesidades que surgen en un territorio determinado como consecuencia de una actividad intensiva en el mismo.

La caza como sector económico no puede desvincularse del sistema global en el que se desarrolla. Es en ella donde cabe entenderla, tanto en sus construcciones teóricas como en las consecuencias derivadas de su acción. La gestión de los distintos terrenos cinegéticos están imbricados, como no puede ser de otra forma, dentro de la lógica capitalista, formando parte de los rudimentos y condicionantes de la economía de mercado. Por su vinculación al medio natural, y por la gestión que en él se realiza, aunque sea bajo una determinada parcialidad, el cazador, en sus discursos, se arroga el apelativo de "verdadero ecologista", partiendo de que efectivamente es él el que actúa por la conservación del medio y de su biodiversidad. Esta definición tiene una trayectoria breve en el tiempo y aparece en oposición al surgimiento de grupos ecologistas y al antagonismo ideológico que se produce con ellos. Sergio dalla Bernardina señala que hay que leer esta definición también como una justificación creada por el cazador en un momento en el que la caza ha perdido su sentido de necesidad y se enfrenta a reflexiones éticas que cuestionan conceptos como el de la tradición y la costumbre. Junto a esta reflexión hay que tener en cuenta que el concepto de "cazador ecologista" viene 


\section{perifèria}

Número 7, mes 2005

\section{www. periferia. name}

condicionado por una concepción económica liberal que defiende que "los problemas ecológicos surgen de la ausencia de racionalidad mercantil privada por la ausencia de 'derechos de propiedad' sobre los recursos y servicios ambientales" (Martínez Alier 1994: 19).

El cazador en la inversión económica que significa cazar no sólo rentabiliza lo gastado sino que protege el medio, de otra forma éste quedaría abandonado y deteriorado al faltar la intervención humana. Una de las causas por las que chocan cazadores y grupos ecologistas es precisamente por la distinta lógica aplicada a nivel económico. La postura del cazador, en líneas generales, se sitúa dentro de los parámetros de la economía neoclásica, basada en el mercado de bienes y servicios, que pone en circulación y que se adaptan a las necesidades de la demanda. Indiferente es que el objeto sea un espacio natural y un contenido vital, y su objetivo una función recreativa, que se carga de significados representativos y que en ocasiones entra dentro de la concepción empresarial. En este sentido, Martínez Alier señala que los movimientos ecologistas participan no de la economía liberal sino de la economía ecológica:

La economía neoclásica analiza los precios (es pues una 'crematística') y tiene una concepción metafísica de la realidad económica que funciona como un perpetuum mobile lubricado por el dinero. Las empresas venden bienes y servicios, y con esto remuneran los factores de producción (tierra, trabajo y capital). La economía ecológica ve el planeta Tierra como un sistema abierto a la entrada de energía solar. La economía necesita entradas de energía y de materiales. La economía produce dos tipos de residuos: el calor disipado (por la Segunda Ley de la Termodinámica), y los residuos materiales, que mediante el reciclaje pueden volver a ser parcialmente utilizados. El funcionamiento de la economía exige un suministro adecuado de energía y materiales ( $\mathrm{y}$ el mantenimiento de la biodiversidad), y también exige poder disponer de los residuos de manera no contaminante. Los servicios que la naturaleza presta a la economía humana no están bien valorados en el sistema de contabilidad crematística propio de la economía neoclásica (Martínez Alier 1994: 42-43). 


\section{perifèria}

Número 7, mes 2005

\section{www.periferia.name}

Optar por una u otra opción supone una variación ideológica que marca profundas diferencias ya que influyen en la acción de cada grupo. Reduciendo la cuestión a un mero elemento económico, la especie cinegética tendría su valor como pieza de caza, las demás no tienen mayor interés que el paisajístico y no se les aplican medidas de conservación. La postura ecologista, al contrario, incide en la importancia de la conservación de los ecosistemas, respetando las cadenas ecológicas, y por tanto dando igual importancia al romero, al conejo, al zorro, al ciervo, al águila y al buitre. Esta interpretación que diferencia las distintas posturas según el paradigma económico escogido viene añadida a la vertiente cultural, que va a condicionar las opciones y acciones, que sólo con una explicación económica pecaría de demasiado determinista. La situación comercial de la caza la tienen presente sus actores. Las nuevas formas difieren de las conocidas y practicadas hace décadas cuando el contexto político, social y económico era diferente. Los discursos que se manejan parten de unas premisas basadas en una idealización de prácticas pasadas y una evolución, aparejada a la técnica y las posibilidades económicas.

En lo referido a la gestión medioambiental chocan las posturas defendidas entre cazadores y grupos ecologistas. A ello habría que añadir las disposiciones administrativas y las políticas cinegéticas, casi nunca del agrado del colectivo de cazadores, y que merecerían un punto aparte. Nos centramos en el primer aspecto. Sobre la gestión medioambiental aparecen diferencias entre cazadores y ecologistas ${ }^{4}$. Éstas estriban en el mismo concepto que se defiende de naturaleza y la actuación que sobre ella se realiza. La caza se basa en una intervención directa sobre el medio con el objeto de erradicar los factores limitantes existentes sobre las especies cinegéticas, de tal forma que se cree un hábitat favorable que permita su expansión y la mejora de sus individuos. En este punto, desde el ecologismo, se respeta la gestión sostenible y adecuada que se realizan en determinados acotados, pero a la vez se pone en duda la eficacia de muchos otros donde hay una práctica

\footnotetext{
${ }^{4}$ Bajo este término nos referimos a los grupos, asociaciones y colectivos ecologistas. Tal vez se pueda pecar de excesiva generalización, lo que se pretende es atender a la postura del colectivo ecologista, entendido como grupo organizado y paralelo a los partidos políticos, y por otro lado de las posturas que en gran medida aparecen dentro de cazadores y organizaciones cinegéticas.
} 


\section{perifèria}

\section{Número 7, mes 2005}

\section{www. periferia.name}

agresiva, que si bien favorece a los terrenos de caza, rompe el equilibrio ecológico, lo que a la larga redundará sobre las primeras y pondrá en peligro su propia existencia. Éste es tal vez uno de los puntos más conflictivos e interesantes. Tantos unos como otros parten de una idea de naturaleza que no es naturaleza, pero que se convierte en el anhelo de un estado puro sobre el que hay que trabajar para su recuperación. Ulrich Beck señala que a los que nos enfrentamos es a una "naturaleza desvirtuada", "desnaturalizada y restaurada" (Beck 1995: 67), que no se puede entender al margen de la sociedad, sino que se ha convertido en sociedad, y "precisamente no es naturaleza, sino un concepto, una norma, un recuerdo, una utopía, una contrapropuesta" (Beck 1995: 68).

A nivel teórico hay una reinvención de la naturaleza, visible en los espacios protegidos, que tiene un fin conservacionista, que surge de una idealidad que en muchas ocasiones se enfrenta con la realidad. Pero si bajamos a la acción se puede observar esa dialéctica entre la idea mítica del "deber ser" y lo que es y cómo se transforma buscando un rendimiento. La caza como actividad inocente que no modifica el medio no es compartida ni siquiera por sus propios actores. En primer lugar se establecen unos límites, físicos mediante tablillas e incluso vallados, y simbólicos, donde la propiedad es de aquel que realiza una actividad atávica, que mantiene el recuerdo de aquello que nos hizo humanos, y que por tanto es el que puede transitar por esos pagos. Se modifica el medio y se parte de una idea que defiende que antes, en un pasado indefinido, habría más caza, más animales, con una naturaleza pura que la caza es la única que puede recuperar y mantener.

El ecologismo parte de la idea de naturaleza como oposición al mundo industrial, a su enajenación y alienación, y busca en ella los valores perdidos, siendo su conservación la única que puede salvar al planeta del colapso ecológico. Hay que restaurar el equilibrio ecológico, hay que proteger y si hace falta restringir la presencia humana, pero también hay que darle un uso social respetuoso, valorativo y democrático, así como imbricarlo dentro de un desarrollo económico sostenible, en el que cualquier ciudadano pueda disfrutar de un patrimonio universal. Los cotos de caza son entonces islas donde no se permite por definición el paso, donde no se restaura el ecosistema sino que se fractura y donde se reproducen en unos 


\section{perifèria}

\section{Número 7, mes 2005}

\section{www. periferia.name}

espacios naturales las relaciones capitalistas. Estas posturas encierran tras de sí un posicionamiento ideológico y político, donde la caza acepta las reglas del juego del sistema capitalista neoliberal, y sus actividades están acorde con el sistema de mercado, mientras que el ecologismo parte de una transformación del mundo apoyándose en el paradigma de la Ecología como ciencia, y en las bases sociales que entroncan con la tradición del socialismo utópico y el anarquismo. La diferencia de planteamiento económico e ideológico entre los dos sectores explica la actitud hacia el medio y la opinión sobre su aprovechamiento.

Cazadores y grupos ecologistas representan dos formas distintas de entender y de actuar dentro de un mismo espacio, al que dotan de un significado diferente, simbolizan y categorizan a partir de unas premisas que están alejadas y que confluyen, cuando lo hacen, en el respeto y conservación natural. Por un lado está la muerte como aprovechamiento y considerar el carácter recreativo de la naturaleza como sistema productivo, mientras que el ecologismo aboga por una conservación global y no parcial del entorno, aunque sus actividades sean locales, fuera de la lógica de mercado o más bien dentro de ella pero con la transformación como objetivo. Esta base económica, o si se quiere decir de otra forma, de rentabilidad, es el gran escollo a salvar entre las dos posturas, más allá incluso que el elemento ético, ya que lo que se plantean son dos concepciones ideológicas diametralmente opuestas, la que comulga con el sistema capitalista, la de los cazadores, y aquella que busca su ruptura con él, la ecologista.

Pero si hay un punto en común es el carácter urbano de los dos movimientos. Ambos, actualmente, proceden de la ciudad, y con ellos traen un concepto determinado de lo que tiene que ser la naturaleza, uno como disfrute recreativo, económico, deportivo, social, y otros como expresión de la realidad en la que vive el planeta y sobre la que hay que actuar urgentemente. Se actúa sobre los mismos terrenos, los protagonistas a defender son los mismos, cambian las acciones y la consideración hacia ellos. El ecologista entiende una caza como entiende el medio, natural, sostenible, en la que no debería existir idealmente la regulación de vedas porque el cazador sería una persona de conocimientos ancestrales que sabría, por ejemplo, la época de cría y tomaría aquello que necesitara, respetando lo demás, 


\title{
perifèria
}

\author{
Número 7, mes 2005
}

www. periferia. name

sin más afán que el fundirse con el medio y ser partícipe de él. Como no existe este ideal, y ni siquiera, en su opinión, se acercan a él, hay que tener un control sobre la actividad y denunciar en todo caso aquellas actitudes que supongan una agresión. El cazador, aunque parte del mismo principio, coincide con el ecologista en que eso ya no existe, ni existirá, y posiblemente no existió, por lo que hay que ordenar la actividad de manera que la caza brinde las expectativas que el cazador busca, para de esa forma restaurar el equilibrio ecológico de los acotados bajo la percepción cinegética actual, es decir, la abundancia y calidad de piezas de caza, no así de aquellos factores que la limiten, convirtiéndose el hombre en hacedor y controlador del medio, que no es más que redundar en la situación de impacto ecológico que sufre el planeta debido a la idea de control total.

La crítica al cazador, hablando siempre a nivel general, viene en gran medida por su carácter puntual, específico, reducido, que si lo globalizara hacia otros problemas podría convertirse en ese verdadero ecologista al que hacen referencia, debido a sus conocimientos y experiencias. Pero no es sólo al cazador el que sufre esta crítica, también se extiende al resto de la sociedad que toma una actitud pasiva, conformista o desinformada de los riesgos ecológicos a los que se enfrenta la humanidad, y no se opone a la actual política que llevará al planeta al colapso y a un cambio radical que afectará al mundo tal y como lo conocemos hoy día.

Dentro del colectivo de cazadores, en numerosos sectores del mismo, hay conciencia sobre los cambios producidos en las últimas décadas en el desarrollo de la caza y en el conjunto del contexto político, social y económico del estado español. Se crea un referente como construcción de valores y actividades más puras, en materia cinegética, que se pierden con el paso de los años, y que fluctúan entre la asunción del atavismo de la práctica, el discurso del "verdadero ecologista" y la actual comercialización.

Un primer punto aceptado en el colectivo es lo que se podría denominar como discurso atávico. Ortega ha hecho referencia a ello al asimilar la caza con un reducto que queda en el hombre producto de su animalidad. El hombre cazador, en un acto que lo ha ido configurando evolutivamente en lo que actualmente es, se convierte en una de las explicaciones al uso, que intenta profundizar en la razón 


\section{perifèria}

Número 7, mes 2005

\section{www.periferia.name}

justificativa última de la práctica cinegética. Es evidente la importancia de la caza en la sociogénesis humana, pero a partir de ahí, y después de cientos de miles de años de existencia, mantener este discurso puede deberse a varias razones: una explicación propia de los cazadores para su afición, una justificación externa ante los no-cazadores y una versión ecológica sobre el control de la naturaleza.

Al preguntar a los cazadores sobre las razones por las que practican la caza, unidas a las de tipo físico, recreativo o de sociabilidad, hay una parte que escapa a la "lógica" y que atribuyen a un instinto natural. Algunos hablan de una llamada del campo, del monte, de la naturaleza, que a pesar de su dureza, del esfuerzo y de la poca recompensa que en muchas ocasiones proporciona, los lleva año tras año, domingo tras domingo, a seguir las perdices o a esperar al jabalí. A ello se refieren como algo que no pueden controlar, un instinto indomable, que no dudan en relacionar, en ausencia de otra explicación, con el carácter primitivo interno. Algunos ejemplos pueden servir:

Conforme transcurren los días, los cazadores se muestran inquietos, con una inquietud soterrada, tímida y vergonzante. Algo en la luz, en la fronda decididamente decadente de los inicios del otoño, les encandila. El Cazador le dice a esto la llamada del campo; otros dicen que es la afición (Delibes 1980: 9).

Es público que lo que primero fuimos como "ser", fue cazadores. Fue el aporte proteico el que permitió el desarrollo cerebral. La paradoja continúa, porque hoy, algunos millones de años después, seguimos siéndolo. La bestia, aún palpita acechando entre nuestros aún eficientes caninos de fiera. No hemos conseguido que nuestro desarrollo mental corra paralelo la de nuestro físico, pues mantenemos la misma dentadura de predador omnívoro apenas "erectus". Los mismos ojos carniceros colocados de frente, para atacar. Parece por tanto que al menos hasta hoy, el hecho cinegético ha tenido razón de ser, merece por tanto ser sentido y pensado. Otra paradoja más. (Andión 2003: 12)

En 1884, José de Argullol hacía referencia a ese carácter atávico de la práctica cinegética: 


\section{perifèria}

Número 7, mes 2005

www.periferia. name

Por tanto, el ejercicio venatorio, á fuer de natural é instintivo, debe remontarse á los primeros momentos en la planta humana holló la tierra: debió comenzar y comenzó tan luégo como los primeros hombre vieron amenazada su existencia, tan luégo como sintieron la necesidad de alimento, y vieron por instinto, en el ave, en el mamífero, el medio de satisfacerlo. Y multiplicáronse los hombres inteligentes y libres: enseñoreáronse del mundo y dominaron á las demás criaturas; y crecieron las necesidades, satisfaciéndolas los animales y las plantas. Aumentaron las familias, formaron tribus, y razas y pueblos, trocando unos lo sobrante por lo sobrante de otros: productos de la tierra, productos de la caza, pieles, plumas, cuernos, huesos, y por ahí se colige que la accion de cazar ha sido practicada por todos los hombres, en todo tiempo, y que en el primitivo debió constituir importante industria; medio sino único, principal y poderoso de atender á la subsistencia" (Argullol 1884: 8)

La internalización del sentimiento atávico sirve como seña de identidad y como elemento de nobleza de la actividad frente a sus detractores. El hecho de practicar algo que se lleva haciendo desde los albores de la humanidad se esgrime frente al no-cazador para la comprensión e importancia de la caza. A su vez, este razonamiento está imbricado con su papel de control ecológico. En un momento donde ésta no es necesaria para la supervivencia, se aboga por su importancia para la supervivencia de las especies cinegéticas. La caza pasa a ser reguladora de la vida en su paradoja de la muerte, así como salvaguarda de espacios que de otra forma habrían desaparecido debido a la presión humana.

Las razones esgrimidas son de tipo cuantitativo, la caza permite la existencia de un mayor número de animales, y cualitativos, estos, sobre todo para la caza mayor, presentan las mejores condiciones debido a su selección como trofeo. La función ecológica es una de las más importantes y repetidas por los cazadores, así como de las más convincentes, aceptadas por el poder político así como por grupos ecologistas que mantienen sus fuertes reticencias no ya contra la caza en sí sino con la forma de realizarla y los intereses económicos que se mueven a su alrededor, que condicionan cualquier tipo de posicionamiento ecológico.

Una elaboración teórica sobre la caza la plantea Patxi Andión, que imbrica el planteamiento de la actividad cinegética como forma de control de equilibrio ecológico a partir de su importancia social y económica: 


\title{
perifèria
}

\author{
Número 7, mes 2005
}

\section{www. periferia. name}

Ya lo hemos dicho. Comprender la caza, asimilar porqué el cazador lo hace y expresarlo a los que no lo entienden no es tarea fácil. Pero hay que proponérselo en serio por costoso que sea. Necesitamos hacernos entender. No oír, sino que se escuche nuestro discurso que no es banal ni inclemente, ni impío, ni ventajista, ni destructor. Es una actitud que dio origen al hombre moderno y que no hemos abandonado desde la noche de los tiempos. Los que hoy, llamándonos cazadores nos consideramos los más responsabilizados con el medio. (...) El ejercicio de la caza ética, racional, es imprescindible para la supervivencia de las especies. Si la practica el cazador deportivo, pagará por ello y la renta vendrá a permitir la existencia de los seres humanos que pueblan el bosque mediterráneo. Si no es así. Serán los guardas los que tendrán que matar como pasó en Cazorla, machos, hembras y crías de forma salvaje e indiscriminada, a costa del contribuyente, una vez que la Reserva estuvo despoblada en la práctica (Andión 2003: 22-24).

Lo analizado hasta ahora lleva indefectiblemente a considerar cómo afectan todas estas cuestiones al medio natural receptor y con una pregunta clásica que aglutina varios aspectos: ¿es el medio natural el que determina la actividad económica o es ésta la que lo condiciona? La hipótesis de partida en el campo cinegético es, como se puede adivinar, que el beneficio económico modela el entorno que lo alberga, hasta niveles tales que desaparece como medio prístino (base de los discursos atávicos) y se convierte en un elemento más del proceso de mercantilización, alterando su composición hasta la completa modificación ecológica.

Las construcciones ideológicas realizadas alrededor de la caza, en el sentido de pérdida de pureza y desarrollo hacia la comercialización, habría que relacionarla con el cambio dentro de un sistema de mercado de una parte de él que todavía mantenía cierta resistencia, y que ha sido vivido por muchos de los cazadores que todavía hoy la practican. En determinadas cacerías aparecían, y de hecho lo siguen haciendo cuando se dan, elementos que no se basaban en el intercambio monetario sino en una producción doméstica, no ya con una idea meramente de subsistencia sino que se compartía dentro de un juego de reciprocidades sociales y que se perpetuaban en ellas. Las monterías por invitación son un ejemplo de esto. No aparece ni transacción ni dinero, incluso se oculta para mostrar su presencia. El dueño de la finca organizaba una cacería a lo que invitaba a amigos, familiares y compromisos, desarrollándose la jornada en este ambiente. El objetivo no era únicamente la caza, entendida como la consecución de mayor número de piezas, sino que primaban otros valores insertos en los códigos propios del grupo que se 


\section{perifèria}

Número 7, mes 2005

www. periferia. name

reunían y que los distinguían como tal. La cohesión social predominaba y no aparecía la comercialización en la venta de puestos, aunque ese extremo no quiere decir que no estuviera dentro de un proceso mercantilizado. El componente recíproco es más fuerte y de él se espera la contraprestación correspondiente. Los tres tipos de reciprocidad señalada, entre otros, por Marshall Sahlins, generalizada, compensada y negativa, podrían darse o no en el contexto analizado, pero servirán en todo caso como idea presente en el grupo. La reciprocidad generalizada, basada en la presunción de que lo dado será devuelto en algún momento, la compensada, como intercambio directo y explícito, y la negativa, la falta de reciprocidad, son categorías analíticas que intentan explicar un hecho social, que en nuestro caso son intergrupales, con una cohesión en los parámetros ideológicos y morales de aquellos que intervienen en ellos. Este conjunto ideal se transforma rápidamente cuando se alternan las monterías por invitación con la venta de puestos, que sirven para financiar la lógica de la reciprocidad mientras que los compradores se sitúan en el mercado, esperando unos resultados acordes al dinero desembolsado.

Las formas de producción cinegética tienen una influencia directa sobre el concepto de caza y la modificación en su práctica. Pero también la tiene sobre el lugar que la alberga y cómo es percibido: se mercantiliza la caza y con ella se modifica el paisaje, las especies y el medio natural.

\section{Las relaciones humano-ambientales y la percepción del medio}

La dicotomía naturaleza-cultura ha sido puesta en entredicho por distintos autores, que inciden en el análisis conjunto y en la interrelación existente entre ambos conceptos, que sobrepasa una mera estrategia metodológica y permite interpretar la realidad humana y medioambiental conjuntamente como elementos inseparables. Descola y Pálsson, en la introducción del influyente volumen Nature and Society. Anthropological perspectives (1996), publicado en castellano en el 2001, recorren brevemente el origen de la dicotomía naturaleza-sociedad y naturaleza-cultura dentro de la disciplina antropológica, criticando y superando esta clásica división, proponiendo un carácter integrador de ambos conceptos que permita un análisis global de la Humanidad y de su estar como parte de la naturaleza (Descola y Pálsson 2001: 30). 


\section{perifèria}

Número 7, mes 2005

www.periferia. name

Partiendo de la premisa de la naturaleza como constructo cultural, sobre la que cada tradición establece una serie de atributos y significados que la definen, realizada a partir de su experiencia directa y siguiendo un correlato dialéctico infraestructural y superestructural, la sociedad occidental, a partir de su orden industrial-capitalista, ha creado también sus propias correlaciones sobre los términos relacionados con el medio natural. Naturaleza aparece como un término sugerente referido a un lugar prístino, primigenio, alejado del impacto del mundo industrial.

Frente al término naturaleza, e influido por el desarrollo de la Ecología, aparecen distintas formas de citar a una misma realidad: medio ambiente, medio natural, ecosistema, entorno natural o espacio natural. Con estos conceptos no se hace referencia a esa naturaleza incontaminada, que no es más que una construcción referencial, sino aquella que entra dentro de la lógica occidental, aquella que percibida como alterada conserva no obstante ciertos atributos, pero que se percibe como modificada por la sociedad industrial.

A partir del s. XIX y la expansión de la revolución industrial, se ha vivido un proceso que ha provocado en menos de dos siglos un cambio ecológico sin precedentes. También hay que tener en cuenta los impactos anteriores a este proceso, que tanto en el marco geográfico que se podría considerar como occidental, como en otros lugares del planeta, y provocados por distintas culturas y necesidades socioeconómicas, se han dado y han dejado su huella impresa en el paisaje.

No hay que atender únicamente al hecho de la adaptación del ser humano al medio y su posterior control, sino que hay que atender a qué percepción se tiene y qué relaciones son las que se establecen, dentro del marco occidental al que hacemos referencia, que condicionan su aprehensión y su dominio. Se ha hecho mención al avance que a nivel teórico pretende superar la clásica dicotomía entre naturaleza y cultura que se ha dado dentro del análisis antropológico, para de esta forma crear nuevas formas de acercamiento a la implicación ecológica entre los dos conceptos. En la sociedad, política y economía occidental, esta tradición está tan arraigada que hay una cada vez mayor separación entre ambas, a pesar de lo que la aparición de 


\section{perifèria}

Número 7, mes 2005

\section{www.periferia.name}

movimientos ecologistas o nuevas formas de consumo pudiera aparentar. La idea que mueve al mundo occidental y que traspasa las fronteras globalizadas es el progreso. El hombre en su dominación de la naturaleza se considera capaz de su creación, destrucción y reconstrucción. Se parte de dos polos, por un lado el humano y por otro el natural, se pierde la idea de que el primero forma parte del segundo, al contrario, la naturaleza está completamente subordinada al control humano.

En el artículo El pensamiento ecologizado, dentro del análisis complejo que propone para el estudio de los fenómenos sociales, Edgar Morin señala esa tradición occidental inmersa en un paradigma que obliga a "pensar al individuo separado de su entorno y de su habitus, estamos habituados a encerrar las cosas en sí mismas como si no tuviesen un entorno". La idea de dominio de la naturaleza, para Morin (2006), debe cesar, el primer paso es de corte ideológico y dentro del mundo científico teórico, volviendo a una idea integradora de elementos naturales y humanos que no son por otro lado inseparables.

Poco a poco el tema se centra buscando la relación que establece la actividad cinegética sobre el medio que la alberga. ¿Encontramos en ella la idea de hombre insular que domina la naturaleza, o aquella otra que aboga por una conjunción del hombre como una parte más de la cadena ecológica? Para ensayar una respuesta cabe referirse a Gisly Pálsson y la distinción de tres modelos de relaciones humanoambientales: orientalismo, paternalismo y comunalismo ${ }^{5}$.

\footnotetext{
5 “Del mismo modo, poniendo el acento en el contraste entre dominación y protección con respecto al medio ambiente, podemos distinguir entre dos tipos radicalmente diferentes de relaciones humanoambientales: el orientalismo y el paternalismo ambientales. La diferencia clave entre ambos es que el primero "explota", mientras que el segundo "protege". El orientalismo ambiental sugiere reciprocidad negativa en las relaciones humano-ambientales, mientras que el paternalismo implica una reciprocidad equilibrada, presuponiendo la responsabilidad humana. Tanto en el orientalismo como en el paternalismo ambiental, los hombres son amos de la naturaleza. Rechazando la separación radical entre naturaleza y sociedad, el objeto y el sujeto, así como las presunciones modernistas de otredad, certeza y monólogo, y agregando la dimensión de continuidad y discontinuidad, obtenemos un tercer paradigma que podríamos llamar comunalismo (véase la fig. 4.1.). Este paradigma sugiere una reciprocidad generalizada en las relaciones humano-ambientales, invocando los conceptos de contingencia, participación y diálogo". (Pálsson 2001: 84)
} 


\title{
perifèria
}

\author{
Número 7, mes 2005
}

www.periferia. name

El paradigma orientalista ambiental ahonda en la división entre naturaleza y sociedad. Señala Pálsson (2001) que su vocabulario es de domesticación, frontera y expansión, a las que habría que añadir el concepto de progreso ilimitado bajo la conciencia de una dominación y una capacidad para controlar y minimizar los posibles impactos. Científicos y técnicos se convierten en elementos fundamentales de control, apoyándose en sus postulados los dirigentes políticos y los grupos de poder económico. Para este modelo no hay problema ambiental ya que el controlador del mismo es el propio sistema.

Otro de los paradigmas es el denominado paternalista, caracterizada por relaciones de protección y no de explotación. El ser humano tiene una responsabilidad sobre sus congéneres y a la vez con las otras especies del mundo animal y con el medio. Se toma conciencia del impacto y se intenta corregir mediante acciones que se encuentran a su vez dentro de las causantes de los impactos. La postura combativa de esta relación viene representada por colectivos ecologistas que consideran que es el ser humano el único que puede proteger a la naturaleza, al ser él su agente destructor, lo que deja entrever a su vez que hay una relación de dominación, una separación entre humanidad y naturaleza, quedando ésta relegada a ejemplos localizados y vírgenes del dominio humano.

Frente a los dos paradigmas anteriores aparece el paradigma comunalista, donde se constata una "reciprocidad generalizada", un intercambio que a menudo se representa metafóricamente en términos de relaciones personales íntimas. Se podría resumir en el ser humano dentro de la naturaleza, como una parte más de ella y dentro de su lógica ecológica.

Pálsson señala que estos tres tipos de relaciones aparecen también en los posicionamientos teóricos y el tratamiento de los textos etnográficos, por lo que no es únicamente una forma de acción sino una descripción e interpretación de ella. De estos paradigmas se toma su condición referido a la descripción de la acción de las relaciones, con el objetivo de tomarlo como elemento de análisis para la interpretación de cómo interactúa a nivel individual y colectivo el cazador con el medio ambiente, y en una postulación más amplia intentar generalizar lo que podría ser un patrón de relación de la caza como actividad con el componente 


\title{
perifèria
}

\author{
Número 7, mes 2005
}

www. periferia. name

natural. Señala las diferencias entre los tres paradigmas, aunque a continuación se refiere a su polifonía, es decir, casos en los que pueden aparecer rasgos de los tres elementos, lo que acertadamente sirve no para una estanqueidad teórica sino para constatar la complejidad de estas relaciones entre sociedad y cultura.

El espacio cinegético, el referente de la naturaleza, se convierte para el cazador en un símbolo que condensa una serie de significados que forman parte de los elementos que definen su actividad. Por un lado estaría el uso que se hace del medio natural, entendido como aquel en el que se desarrolla la caza, y por otro el valor de referencia, la construcción simbólica para establecer la analogía con la caza. De este punto surge la relación de conservación, en el sentido que para preservar el medio natural se debe hacer uso de él, y en el caso cinegético convirtiéndose en actividad reguladora para su correcto funcionamiento. Dentro de la transmisión de conocimientos entre cazadores, la naturaleza en su vertiente simbólica se llena de connotaciones de pureza, de primitividad, equilibrio, donde la intervención humana lo es de igual a igual, respetando unas normas no escritas, como parte de la cadena ecológica. La caza se relaciona en todo este momento representativo con la naturaleza, siempre como actividad inocente o beneficiosa, nunca impactante en sentido negativo. De la transmisión de este conocimiento deriva la clasificación de los cazadores, pero también sirve como arma arrojadiza frente a sus detractores, al considerar que no conocen y por tanto no valoran ese medio que quieren proteger. La percepción es distinta y por tanto su construcción, a partir de ahí también lo es la acción.

El cazador se considera como benefactor de la naturaleza, incluso, en ocasiones, el único debido que gracias a su trabajo se mantienen especies cinegéticas y el hábitat que las acoge. El posible impacto se diluye de esta forma siendo más numerosos los pro que los contra. El análisis planteado recae tanto en la existencia del impacto, atendiendo a una evidencia objetiva, como a la percepción que se posee desde el grupo que lo realiza. En líneas generales no se puede hablar de una actitud que se basa en una igualdad de condiciones, una relación paritaria entre hombre y medio natural, aunque éste sea uno de los ejes del discurso, sino en un sentido, como se ha visto, de propiedad y/o apropiación. En ello influye el 


\section{perifèria}

\section{Número 7, mes 2005}

\section{www.periferia.name}

componente comercial que adquiere la caza en España a partir de los años ochenta, generalizándose cada vez más desde hace una década.

La aprehensión del espacio, el concepto de territorio, lugar y no-lugar, para el caso cinegético, se desarrolla a partir de los valores de uso que se le confiere, de la posición que se les otorga dentro de la reflexión general, y de la acción, a partir de esta situación y recíprocamente. El impacto medioambiental se ubica en estas coordenadas, con una relación de conciencia y acción, donde no sólo se documentan construcciones ideológicas sino también actos económicos, relacionados con los primeros o autónomos, que buscan en ellos su referencia justificativa. Las relaciones humano-ambientales se estructuran en la tensión entre la construcción ideal, creada y recreada en los discursos cinegéticos donde la naturalidad es un referente básico, y la realidad económica y social de la caza, con una exigencia monetaria importante para el usuario y unos beneficios elevados para las empresas del sector. Es en este momento cuando el referente natural se ve sometido a las exigencias del mercado, y las prácticas "ecológicas" de conservación tienen un trasfondo de rentabilidad económica.

Si Robert Ardrey formuló la "hipótesis del cazador" para explicar el proceso de hominización y la evolución hasta el Homo Sapiens, la hipótesis del "verdadero ecologista" justifica la situación de ese cazador en un tiempo y lugar donde la caza ha perdido su componente de subsistencia y su condicionante evolutivo. Dentro de la sociedad occidental, industrializada y postindustrializada, moderna y postmoderna, la etiqueta ecológica, se convierte en un término condensatorio con una carga positiva. Ser ecológico es comprometerse solidariamente con la mejora y el bienestar común, además de con uno mismo en un conjunto que integra beneficios individuales, propiciados por la vuelta a la naturaleza, con la comunidad, al practicar y propiciar actividades supuestamente no contaminantes. Lo ecológico, lo verde, vende, tanto en el sentido más comercial de la palabra como en el ideológico, donde los partidos políticos, independientemente de sus presupuestos políticos y económicos, buscan la imagen ecológica como intereses publicitarios que oculten sus políticas pasadas, presentes y futuras. 


\section{perifèria}

\section{Número 7, mes 2005}

\section{www. periferia.name}

No cabe duda que la gestión y la práctica cinegética tiene una influencia directa sobre el medio, debido al hecho de la propiedad y la posibilidad de acción sobre el terreno. Tampoco hay que dejar de señalar que su actividad propicia la conservación de muchos espacios naturales que de otra forma se encontrarían en situaciones difíciles, y que la caza fue fundamental en el origen de la creación de los espacios protegidos a principios del siglo XX en el estado español. Se actúa, se modifica y se propicia, no hay que dudarlo, la vida y la conservación, aunque sea cinegética. Es la base de estos discursos, y en parte la realidad le da la razón. Desde un razonamiento parcial la explicación tiene visos de ser casi perfecta, viniendo sus flecos de la base comercial en la que se basan numerosos acotados. Desde una reflexión global, la actuación puntual conlleva dejar al margen otras reflexiones que vendrían a poner en cuestión ese concepto de verdadero ecologismo, contextualizándolo dentro de una práctica que no puede sustraerse hoy día de su importancia económica y social.

\section{Bibliografía}

Álvarez Munárriz, L. (2007). “Conciencia y conducta medioambiental: los paisajes culturales", en Intersticios. Revista Sociológica de Pensamiento Crítico, Universidad de Murcia.

Andión, P. (2003). La Caza Racional. Albacete: Ediciones de la Universidad de Castilla-La Mancha.

Argullol, J. (1884). La caza bajo el punto de vista histórico, filosófico e higiénico. Madrid: Facsímil.

Beck, U. (1998). Políticas Ecológicas en la Edad del Riesgo. La irresponsabilidad organizada, Barcelona: El Roure.

Beck, U. (2001). [1986]. La sociedad del riesgo. Hacia una nueva modernidad. Madrid,: Paidós.

Comas d'Argemir, D. (1998). Antropología económica, Barcelona, Ariel.

Dalla Bernardina, S. (1996). Il ritorno alla Natura. L' utopia verde tra caccia ed ecologia, Mondadori Editore.

Dalla Bernardina, S. (1989). «L'invention du chasseur écologiste : Un exemple italien », en Terrain, Numéro 13. 


\section{perifèria}

Número 7, mes 2005

www. periferia. name

Delibes, M. (1980). Dos días de caza, Barcelona, Destinolibro.

Descola, P. y Pálsson, G. (2001). [1996] Naturaleza y Sociedad. Perspectivas antropológicas.

México: S. XXI editores.

Ingold, T. (2000). The perception of the environment. Essays in livelihood, dwelling and skill, London: Routledge.

Molina, J.L. y Valenzuela, H. (2007). Invitación a la antropología económica. Barcelona: Ediciones Bellaterra.

Morin, Edgar (1996). "El pensamiento ecologizado", en Gazeta de Antropología, 12, Universidad de Granada. http://www.ugr.es/ pwlac/G12_01Edgar_Morin.html

Morin, Edgar (2005). [1973] El paradigma perdido. Ensayo de bioantropología, Barcelona, Editorial Kairós.

Ortega y Gasset, J. (1995). El espectador (Antología), Madrid: Alianza Editorial.

Ortega y Gasset, J. (1999). [1941] Sobre la caza, los toros y el toreo, Madrid: Revista de Occidente en Alianza Editorial. 